\title{
Impact of fluctuating patterns of bronchiolitis epidemics in infants
}

\author{
Bernhard Resch
}

Received: 26 January 2012 / Accepted: 21 February 2012 /Published online: 7 March 2012

(C) Springer-Verlag 2012

To the Editor,

Walker and coauthors [5] recently reported on the effects of introducing a new clinical care pathway in the management of bronchiolitis in infants aged below 6 months. They observed a significant reduction in the use of salbutamol and ipratropium bromide, and an overall reduction in the duration of hospital stay while the prescription rate of antibiotics remained unchanged. In their study two seasons $(2003 / 2004$ and 2004/2005) were compared with the following five seasons and findings were attributed to the introduction of a new clinical pathway. If one compared the first two seasons with the 2007/2008 and 2008/2009 seasons, no difference in the length of hospital stay would have been observed questioning the real effects of this new clinical pathway. The fluctuating patterns of bronchiolitis epidemics throughout the northern hemisphere are well-known, making comparisons between seasons and any connections with changed treatment regimens highly sophisticated and sometimes speculative. In a recent study, we demonstrated long-term epidemiological data on respiratory syncytial virus (RSV) seasons over 16 years [3]. Data would have allowed us to compare a lot of clinical parameters in the management of infants being hospitalised for RSV lower respiratory tract infection that might have resulted in significant findings over some seasons, but at least might have been found only by change due to the changing patterns of the epidemic seasons.
Another interesting finding of the study of Walker et al. [5] is the unchanged rate of antibiotic treatment in up to $25 \%$ of bronchiolitis cases. Real bacterial coinfection is reported in up to $2 \%$ of cases being not admitted to the intensive care unit [2]. Thus, efforts are still needed to reduce antibiotic prescription in infants hospitalised due to bronchiolitis even in the case of elevated inflammatory indices except when septic work-up reveals positive bacterial cultures [1]. But this might not be the case for infants with severe bronchiolitis being admitted to the ICU [4] that have significantly higher rates of bacterial coinfections.

\section{References}

1. Resch B, Gusenleitner W, Müller W (2003) Procalcitonin, interleukin-6, C-reactive protein and leukocyte counts in infants with bronchiolitis. Pediatr Infect Dis J 22:475-476

2. Resch B, Gusenleitner W, Mueller WD (2007) Risk of concurrent bacterial infection in preterm infants hospitalized due to respiratory syncytial virus infection. Acta Paediatr 96:495-498

3. Resch B, Sommer C, Nuijten MJ, Seidinger S, Walter E, Schoellbauer V, Mueller WD (2012) Cost-effectiveness of palivizumab for respiratory syncytial virus infection in high-risk children, based on long-term epidemiologic data from Austria. Pediatr Infect Dis J 31:e1-e8

4. Spurling GK, Doust J, Del Mar CB, Eriksson L (2011) Antibiotics for bronchiolitis in children. Cochrane Database Syst Rev 15:CD005189

5. Walker C, Danby S, Turner S (2011) Impact of a bronchiolitis clinical care pathway on treatment and hospital stay. Eur J Pediatr. doi:10.1007/s00431-011-1653-9, published online 23 Dec 2011

B. Resch $(\triangle)$

Department of Paediatrics, Research Unit for Neonatal Infectious

Diseases and Epidemiology, Division of Neonatology,

Medical University of Graz,

Auenbruggerplatz 30,

8036 Graz, Austria

e-mail: bernhard.resch@medunigraz.at 